\title{
ENTRE LA HISTORIA Y LA MEMORIA. A 40 AÑOS DEL GOLPE DE ESTADO EN LA ARGENTINA
}

\author{
Between history and memory. 40 years after the coup \\ d'état in Argentina
}

\author{
Emilio Crenzel*
}

\begin{abstract}
RESUMEN
Este artículo historiza las etapas que ha recorrido, desde hace cuarenta años cuando se produjo el último golpe de Estado, la memoria social de la dictadura y el período de violencia política que recorrió la Argentina durante los años setenta del siglo XX y su figura emblemática, los desaparecidos. Luego de trazar un perfil general de las dimensiones cuantitativas y cualitativas de la violencia de Estado que atravesó el país, se presentan los diversos contextos políticos e institucionales que signaron cada etapa por el cual atravesó la memoria social sobre este proceso, los actores principales que intervinieron en las luchas por dotar de sentido a este pasado, y las claves narrativas e interpretativas que enarbolaron en esos enfrentamientos. El artículo propone y demuestra que la historia de la memoria no es resultado directo de la voluntad del poder y que, en el caso argentino, la memoria dominante ha sido y es producto de las iniciativas de verdad y justicia que propuso, en diversas coyunturas, el movimiento de derechos humanos. Esa perspectiva fue, luego, asumida por diversas conducciones del Estado. En cambio, las propuestas de olvido e impunidad, impulsadas por diversas conducciones estatales, fueron derrotadas por la hegemonía construida, en la esfera pública, por el movimiento de derechos humanos respecto a cómo tramitar las violaciones a los derechos humanos sucedidas en el país.
\end{abstract}

Palabras-clave: Argentina, Cuarenta años, Golpe de Estado. de Buenos Aires.

* Consejo Nacional de Investigaciones Científicas y Técnicas (CONICET)-Universidad 


\begin{abstract}
This article historicizes the stages, since the last coup d'état, of the construction of the social memory of the dictatorship and the period of political violence of 1970s Argentina and its emblematic figure, the disappeared. It begins with a general outline of the quantitative and qualitative dimensions of the state violence that affected the country during this process, and goes on to examine the various political and institutional contexts that marked each stage of the social memory of these processes, the actors engaged in the struggles to give meaning to that past, and the key narrative and interpretative strategies deployed in such confrontations. The article proposes and demonstrates that the history of the social memory of the human rights abuses is not a direct result of the will of the power and. On the contrary, in the case of Argentina, the dominant memory has been and is a product of the initiatives of truth and justice proposed, at various junctures, by the human rights movement. That perspective was then taken over by various state governments. Instead, the proposals of forgetfulness and impunity, launched by several state governments were defeated by the hegemony built, in the public scenario, by the human rights movement regarding how to deal with human rights violations occurred in the country.
\end{abstract}

Keywords: Argentina, Forty years, Coup d'état.

\title{
Introducción
}

El Parque de la Memoria, a orillas del Río de La Plata en Buenos Aires, fue escenario de un hecho original al conmemorarse los 40 años del golpe de Estado de 1976. La escena hubiese resultado inverosímil años atrás. Por primera vez, un presidente de los Estados Unidos y un presidente argentino, miembro de la élite económica local, coincidían en pronunciarse sobre el golpe en un sitio de memoria y en un acto oficial. Barack Obama y Mauricio Macri, contemplaron con gesto serio el "Monumento a las víctimas del terrorismo de Estado", en el cual se inscriben los nombres de los desaparecidos y asesinados y arrojaron flores al río para homenajearlos. Luego, coincidieron en condenar ese pasado y recurrieron, para ello, a una frase emblemática: "Nunca Más". Obama, afirmó que los Estados Unidos "tardaron" en defender los 
derechos humanos, obliterando su apoyo al golpe, se comprometió a desclasificar documentación oficial sobre el período, reconoció la lucha y la valentía de los familiares de las víctimas y los propuso como la garantía del Nunca Más. Macri, por su parte, condenó la violencia "política e institucional" y recordó a "las víctimas que han pagado con su vida estas intolerancias y divisiones entre los argentinos" despojando, así, de toda dimensión distintiva a la violencia dictatorial, cuyo aniversario conmemoraba, y a sus víctimas concretas. ${ }^{1}$ La asistencia de los presidentes al Parque de la Memoria y sus discursos son resultado y expresión de una larga historia de luchas por escribir la historia e inscribir en la memoria el significado de la dictadura y de sus víctimas. De esa historia y esas memorias tratan estas páginas.

La violencia política que atravesó Argentina en la década de 1970 y principios de los años ochenta no fue ajena a su vida institucional entre 1930 y 1975, y al nuevo contexto internacional de la segunda postguerra. Desde 1930 hasta 1983 se sucedieron en Argentina una docena de golpes de Estado encabezados por las fuerzas armadas. Desde entonces, el intervencionismo militar en la escena institucional fue normalizado por amplios sectores de la sociedad civil y política. La intervención castrense, junto a la influencia de las ideas nacionalistas, conservadoras y del integrismo católico, conformaron una cultura signada por el desprecio a la ley y la alteridad. La tortura contra los presos políticos adquirió un carácter regular y el recurso a la violencia un estatus privilegiado. ${ }^{2} \mathrm{~A}$ mediados de los años cuarenta, el surgimiento del peronismo, conducido por el coronel Juan Perón, de perfil industrialista y que incorporó de manera subordinada en una alianza de clases al movimiento obrero a la vida política, generó en el país una polarización política acentuada en 1955 tras su derrocamiento y

1 "Obama y Macri rindieron homenaje a las víctimas de la dictadura y coincidieron en el reclamo de "Nunca más" La Nación, 24 de marzo de 2016. Disponible en http://www.lanacion.com.ar/1883023-barack-obama-mauricio-macri-homenaje-victimas-golpemilitar-parque-de-la-memoria [Consulta: 23 de julio de 2016].

2 Sobre el intervencionismo militar, véase GARCÍA, Prudencio. El drama de la autonomía militar, Madrid: Alianza, 1995. Sobre la influencia de las ideas nacionalistas y católicas, véase ZANATTA, Loris. Del estado liberal a la nación católica. Iglesia y ejército en los orígenes del Peronismo 1930-1943. Quilmes: Universidad Nacional de Quilmes, 1996. 
proscripción. Desde entonces, y en el marco de la guerra fría y la victoria de la Revolución cubana, se abrió un ciclo de inestabilidad institucional, agitación social y radicalización política que incluyó el surgimiento de guerrillas marxistas y peronistas. Las fuerzas armadas adoptaron la idea de que tenían como misión institucional combatir a la "subversión" e incorporaron las experiencias francesas de guerra en Argelia e Indochina y la Doctrina de Seguridad Nacional norteamericana, que incluían la tortura, la consideración de que la guerra era total y que el enemigo podía hallarse en toda la sociedad. ${ }^{3}$

El regreso de Perón al gobierno en 1973 no clausuró la violencia. Las organizaciones guerrilleras retomaron la lucha armada y comenzó a operar, con apoyo oficial, la Alianza Anticomunista Argentina, la "Triple A", que asesinó a centenares de opositores políticos. Tras la muerte de Perón, asumió la presidencia su viuda, María Estela Martínez, quien declaró el 6 de noviembre de 1974, por decreto 1.368, el estado de sitio y, en febrero de 1975, por el decreto 265 , autorizó a las fuerzas armadas a aniquilar el accionar subversivo en la provincia de Tucumán extendiendo, en octubre de 1975, por el decreto 2.772 , esa autorización a todo el país. La violencia política se volvió cotidiana.

En ese marco se produjo el golpe de Estado de 1976, tras el cual las desapariciones se volvieron sistemáticas. Consistían en la detención o el secuestro de personas, efectuado por militares o policías; su reclusión en lugares ilegales de cautiverio, generalmente ubicados en dependencias militares o policiales, donde eran torturadas y, mayoritariamente, asesinadas. Sus cuerpos eran enterrados en tumbas anónimas, incinerados o arrojados al mar; sus bienes saqueados y las Abuelas de Plaza de Mayo estiman en 500 los hijos de desaparecidos apropiados por las fuerzas represivas y cuyas identidades fueron falseadas. De ellos, las Abuelas restituyeron hasta

3 La influencia francesa se extendió en las filas castrenses con la difusión del integrismo católico que combinaba el anticomunismo y el antiliberalismo mediante la creación, en 1957, de las primeras vicarías militares. Entre 1950 y 1975, 3.676 militares argentinos recibieron instrucción en academias militares norteamericanas. Véase DUHALDE, Eduardo Luis. El Estado terrorista argentino. Buenos Aires: Argos-Vergara, 1983, 39. 
julio de 2016 la identidad de 120. Simultáneamente, el Estado negaba toda responsabilidad en los hechos. ${ }^{4}$

Los organismos de derechos humanos postulan la existencia de 30.000 desaparecidos, pero hasta 2016 la Secretaría de Derechos Humanos de la Nación registró 7.018 casos, 1.613 asesinados; 2.793 sobrevivientes de los Centros Clandestinos de Detención (CCD) y estaba procesando 1000 denuncias adicionales. ${ }^{5}$ Como sostiene Brisk, la cifra de desaparecidos está condicionada por la propia naturaleza del crimen; la negativa de los perpetradores a divulgar los registros en su poder; el papel que ciertos actores juegan enarbolando sus propias cifras en la esfera pública y los contextos políticos que enmarcan las disputas por este dato. ${ }^{6}$ El $80 \%$ de las desapariciones ocurrió en las principales ciudades del país (Buenos Aires, el conurbano bonaerense, Córdoba, La Plata, Rosario y Tucumán); $81 \%$ de los desaparecidos tenía, al ser secuestrado, entre 16 y 35 años y $73 \%$ eran hombres.

El $30 \%$ de los desaparecidos eran obreros, $21 \%$ estudiantes, $18 \%$ empleados y $11 \%$ profesionales. La mayoría, integraba organizaciones peronistas y marxistas, guerrilleras o clasistas. Más de 10.000 personas estuvieron en condición de presos políticos; 1.613 fueron asesinadas y se estima que 250 mil, sobre una población para 1975 de 25 millones de habitantes debieron exiliarse. Toda la población fue privada de derechos civiles y políticos. ${ }^{7}$

4 Fuente: Centro de Estudios Legales y Sociales http://www.cels.org.ar [Consulta: 23 de julio de 2016] y Abuelas dePlaza de Mayo, http://www.abuelas.org.ar [Consulta: 23 de julio de 2016].

5 Fuente: Ministerio de Justicia y Derechos Humanos, Secretaría de Derechos Humanos, Registro Unificado de Víctimas del Terrorismo de Estado http://www.jus.gob.ar/derechoshumanos/areas-tematicas/ruvte.aspx [Consulta: 23 de julio de 2016].

6 BRISK, Alison. The politics of measurement. The contested count of the disappeared in Argentina. Human Rights Quarterly, Baltimore: Johns Hopkins University Press, 16, (4) (1994): 676-692.

7 Para la cifra de exiliados, véase BERTONCELLO, Rodolfo y LATTES, Alfredo. Medición de la emigración de argentinos a partir de la información nacional. En LATTES, Alfredo y OTEIZA, Enrique (eds.). Dinámica migratoria argentina (1955-1984) Democratización y retorno de los expatriados. Buenos Aires: Centro Editor de América Latina, 1987, pp.39-50. 


\section{La dictadura y las violaciones a los derechos humanos (1976-1983)}

Las desapariciones promovían entre los familiares de los desaparecidos ciclos de angustias y expectativas una y otra vez renovados. Aunque sus allegados presumieran que los desaparecidos estaban cautivos, ignoraban la localización y duración del cautiverio. En la mayoría de los casos, la inexistencia de cuerpos y tumbas borró la distinción que supone el cementerio entre el mundo de los vivos y el de los muertos e impidió la práctica de ritos, como el velatorio y el funeral, que ayudan a elaborar la pérdida. ${ }^{8}$ También, implicaron un quiebre en la historia de la violencia política en Argentina al desplazar la presencia pública y con responsables de la muerte política por su ejercicio clandestino y anónimo.

Tras casi dos años de rechazar la existencia de desaparecidos, o de negar mediante las respuestas a los miles de hábeas corpus presentados por los familiares de desaparecidos ante instancias oficiales, cualquier interés del Estado en las personas reclamadas, en diciembre de 1977 en conferencia de prensa, el presidente de facto Jorge Videla señaló que:

En toda guerra hay personas que sobreviven, otras que quedan incapacitadas, otras que mueren y otras que desaparecen [...]. La desaparición de algunas personas es una consecuencia no deseada de esta guerra. Comprendemos el dolor de aquella madre o esposa que ha perdido a su hijo o marido, del cual no podemos dar noticia, porque se pasó clandestinamente a las filas de la subversión, por haber sido presa de la cobardía y no poder mantener su actitud subversiva, porque ha desaparecido al cambiarse el nombre y salir clandestinamente del país o porque en un encuentro bélico su cuerpo al sufrir las explosiones, el fuego o los

8 DA SILVA CATELA, Ludmila. No habrá flores en la tumba del pasado: la experiencia de reconstrucción del mundo de los familiares de desaparecidos. La Plata: Al Margen, 2001, 114-119 y 122-123. 
proyectiles, extremadamente mutilado, no pudo ser reconocido, o por exceso de represión (La Prensa, 15 de septiembre de 1977, 2 y 3 ).

Así, la dictadura describía a los desaparecidos como guerrilleros y explicaba sus desapariciones por el estado de guerra, como prácticas de la "subversión" o como hechos aislados de la represión.

El pronunciamiento de Videla obedeció a la creciente presencia pública de la Liga Argentina por los Derechos Humanos fundada en 1937; del Servicio de Paz y Justicia formado en 1974 bajo la idea de la no violencia; de la Asamblea Permanente por los Derechos Humanos (APDH) creada en 1975 ante la creciente violencia política; del Movimiento Ecuménico por los Derechos Humanos creado en 1976 y formado por grupos religiosos de diversas iglesias; del Centro de Estudios Legales y Sociales (CELS), desprendimiento de la APDH fundado en 1979, y de las organizaciones de familiares de víctimas: Familiares de Detenidos y Desaparecidos por Razones Políticas creado en 1976 y las Madres de Plaza de Mayo y Abuelas de Plaza de Mayo que, en abril y octubre de 1977, agruparon a madres y abuelas de desaparecidos respectivamente. Este heterogéneo movimiento, mediante la recopilación de denuncias, la presentación de reclamos en diversos foros y medios de comunicación en el país y el exterior; movilizaciones públicas, como las rondas de las madres en torno a la pirámide de la Plaza de Mayo, frente a la Casa Rosada, sede del gobierno argentino, comenzó a demandar al Estado información sobre el destino de los desaparecidos. Su reclamo, se articuló con las denuncias de las organizaciones de exiliados como la Comisión Argentina de Derechos Humanos (CADHU) y el Centro Argentino de Información y Solidaridad (CAIS), localizadas en México, España, Francia y Venezuela; las organizaciones transnacionales de derechos humanos, como Amnesty International, que incluso realizó una inspección in situ en 1976, y los reclamos del gobierno de los Estados Unidos -bajo la presidencia de James Carter- y de países europeos como Francia y Suecia. 
En un contexto signado por el terror y la estigmatización de los perseguidos, retratados por la dictadura como parte de la "subversión internacional" y la simultánea atribución de las fuerzas armadas de la representación de los valores patrióticos y morales, entendidos como naturales de la civilización "occidental y cristiana", los familiares de desaparecidos y los organismos de derechos humanos comenzaron a presentar a los desaparecidos en sus denuncias a partir de sus datos identitarios básicos, como sus edades y sexos; mediante categorías comprensivas, como sus nacionalidades, creencias religiosas, ocupaciones y profesiones, y resaltando sus valores morales y familiares. $^{9}$ Estas categorías restituían la humanidad negada a los desaparecidos y subrayaban el carácter amplio e indiscriminado de la violencia del "Estado terrorista" y la "inocencia" de sus víctimas, ajenas a todo compromiso político, en especial el guerrillero. Las denuncias no ubicaban en un contexto histórico las violencias de Estado, proponiendo el enfrentamiento en términos de víctimas y victimarios, desplazando la matriz marxista de la lucha de clases o el binomio entre el pueblo y la oligarquía, predominantes en las denuncias de la militancia radicalizada antes del golpe. Con igual sentido, la legitimación de la violencia política fue reemplazada por la defensa de principios liberales: el derecho a no ser torturado, objeto de desaparición, ejecución extrajudicial o arresto arbitrario. La verdad asumió, así, un carácter factual y el relato de los sufrimientos corporales se convirtió en su eje medular.

Esta presentación del alegato de denuncia obedeció, además, como demostró Markarian para el caso uruguayo, a las nuevas relaciones establecidas por los denunciantes de la dictadura con las redes transnacionales de derechos humanos. Estos lazos significaron la incorporación de la cultura de los derechos humanos, en expansión en la arena internacional en los años setenta del siglo XX. ${ }^{10}$

En septiembre de 1979 arribó al país una misión de la Comisión Interamericana de Derechos Humanos (CIDH), tras haber

9 Véase FILC, Judith. Entre el parentesco y la política: familia y dictadura, 1976-1983. Buenos Aires: Biblos, 1997.

10 MARKARIAN, Vania. Idos y recién llegados. La izquierda uruguaya en el exilio y las redes transnacionales de Derechos Humanos 1967-1984. México: Uribe y Ferrari Editores, 2006, 104-105. 
recibido centenares de denuncias por desapariciones. En medio del rechazo dictatorial y de innumerables organizaciones sociales y políticas que objetaron su "intromisión en los asuntos internos" del país, recibió denuncias en las principales ciudades y la APDH le entregó las denuncias que había recopilado hasta entonces. También, inspeccionó dependencias militares y policiales, como la Escuela de Mecánica de la Armada (ESMA) y la Coordinación Federal en la Capital Federal y La Rivera en la provincia de Córdoba, denunciadas como "centros clandestinos de detención", término que desde entonces se volvió dominante para denominar a los lugares donde estaban cautivos los desaparecidos, y cementerios públicos donde existían tumbas N.N, abreviatura en latín de "nomen nescio", "nombre desconocido", usada en sepulturas de identidad ignorada.

El informe de la CIDH, publicado en abril de 1980, aseguraba haber recibido 5.580 denuncias de desapariciones, y atribuyó la responsabilidad de dichas desapariciones a una decisión de los "más altos niveles de las fuerzas armadas". Además, manifestó "su preocupación por los miles de detenidos desaparecidos que por las razones expuestas en este informe se puede presumir fundadamente que han muerto" y recomendó, entre otras medidas, enjuiciar y sancionar a los responsables. Días antes de la visita de la $\mathrm{CIDH}$, la dictadura promulgó la ley 22.068, que suponía la presunción de fallecimiento de las persona cuya desaparición hubiese sido denunciada y de la que no se hubieran tenido noticias sobre su suerte, ley que los organismos de derechos humanos y la CIDH rechazaron. ${ }^{11}$ Desde entonces, la consigna "aparición con vida" se tornó central para las Madres de Plaza de Mayo, renuentes a aceptar la muerte de sus hijos sin que se determinarse sus circunstancias y se identificara a los responsables.

Éstas y otras denuncias fueron neutralizadas con relativo éxito por la dictadura, la cual sólo tras la derrota argentina ante el Reino Unido en la guerra de las islas Malvinas, en junio de 1982, perdió consenso interno e internacional. A diferencia del resto de los países del Cono Sur de América latina, la dictadura no pudo

11 COMISIÓN INTERAMERICANA DE DERECHOS HUMANOS. Informe sobre la situación de los derechos humanos en Argentina. Washington: OEA, 1980, 13-18 y 147-152. 
imponerle a la oposición política -la cual sólo entonces objetó los métodos usados en la "lucha antisubversiva"-, condiciones pactadas para la transición a la democracia. Por ello, en medio del rechazo público, cercano al $70 \%$ según las encuestas de opinión, sancionó el 22 de septiembre de 1983, un mes antes de los comicios, la ley 22.924 de "pacificación nacional" conocida como "Ley de Autoamnistía", declarando extinguidas las causas penales por delitos cometidos durante la "lucha antisubversiva". Mientras Italo Luder, candidato a presidente por el peronismo, aseveró la irreversibilidad de sus efectos jurídicos, Raúl Alfonsín, el candidato de la Unión Cívica Radical, se pronunció por derogar la ley por inconstitucional. ${ }^{12}$ En ese contexto, las denuncias de las organizaciones de derechos humanos recibieron atención pública. Desde la "Marcha por la vida", en octubre de 1982, que reunió a 100.000 personas, incorporaron la consigna de "juicio y castigo a todos los culpables" la cual, desde entonces, fue central en sus demandas. Interpelando al futuro gobierno constitucional, articularon su demanda de justicia retributiva con el reclamo de constituir una comisión bicameral que investigaran todas las prácticas del "terrorismo de Estado".

\section{La lucha por los alcances de la verdad y la justicia (1983-1990)}

Tres días después de asumir la presidencia el 10 de diciembre de 1983, Raúl Alfonsín derogó por inconstitucional la ley de "autoamnistía" y ordenó enjuiciar a siete jefes guerrilleros del

12 Para la Ley de "Pacificación nacional", véase Boletín Oficial de la República Argentina, núm. 25.266, 27 de septiembre de 1983: 2 y 3. Para la encuesta de opinión sobre la ley de autoamnistía, véase GONZÁLEZ BOMBAL, Inés. Nunca Más. El juicio más allá de los estrados. En ACUÑA, Carlos., GONZÁLEZ BOMBAL, Inés; JELIN, Elizabeth; LANDI, Oscar; SMULOVITZ, Catalina; QUEVEDO, Luis y VACCHIERI, Susana., Juicio, castigos y memorias. Derechos Humanos y justicia en la política Argentina, Buenos Aires: Nueva Visión, 1995, 193-216. 
Ejército Revolucionario del Pueblo y de Montoneros por actos de violencia cometidos desde 1973 y a las tres primeras juntas de la dictadura por homicidio, privación ilegítima de la libertad y torturas, ya que la desaparición forzada no estaba tipificada en el Código Penal. Esta disposición fue denominada la "teoría de los dos demonios", pues limitaba a dos actores la responsabilidad por la violencia y postulaba a la violencia de Estado como respuesta a la guerrilla.

Alfonsín propuso que los tribunales militares juzgasen, en primera instancia, las violaciones -imaginando que las fuerzas armadas se autodepurarían-, con posibilidad de apelar a la Cámara Federal y el principio de presunción de obediencia sobre los actos cometidos según planes de la junta militar. Se distinguirían tres categorías de autores: "los que planearon la represión y emitieron las órdenes; quienes actuaron más allá de las órdenes, movidos por crueldad, perversión, o codicia, y quienes las cumplieron estrictamente". Sólo las dos primeras serían enjuiciadas ya que se sostenía que la naturaleza jerárquica militar y el contexto ideológico que enmarcó la represión impidieron desobedecer las órdenes y discernir su naturaleza. ${ }^{13}$ Así, esta propuesta buscaba materializar un castigo ejemplar, desde una perspectiva disuasiva de la pena. Los juicios fueron rechazados por las fuerzas armadas que reclamaron el reconocimiento por su victoria ante la "subversión", y por los organismos de derechos humanos que demandaron que actuase la justicia civil y el "juicio y el castigo a todos los culpables" de la represión.

Asimismo Alfonsín creó, el 15 de diciembre, la Comisión Nacional sobre la Desaparición de Personas (CONADEP) para investigar el destino de los desaparecidos. La CONADEP fue rechazada por las fuerzas armadas y sus aliados que se negaban a que se revisase la "lucha antisubversiva" y por los organismos que pedían una comisión parlamentaria bicameral. La CONADEP, compuesta por personalidades de la sociedad civil y tres diputados de la nación, tenía como metas recibir denuncias y pruebas sobre las desapariciones

13 NINO, Carlos. Juicio al mal absoluto. Los fundamentos y la historia del juicio a las juntas del proceso. Buenos Aires: Emecé, 1997, 106 y 107. 
y remitirlas a la justicia; averiguar el destino de los desaparecidos, incluyendo los niños sustraídos por las fuerzas represivas; denunciar a la justicia el ocultamiento o destrucción de pruebas y emitir un informe final. Tras recibir miles de denuncias de familiares y sobrevivientes de las desapariciones, examinar documentos oficiales e inspeccionar cerca de cincuenta centros clandestinos de detención en todo el país, el 20 de septiembre de 1984 entregó al presidente su informe Nunca más, constituyéndose así en la primera comisión de la verdad en el mundo en cumplir con sus objetivos.

De estilo factual y realista, e incluyendo testimonios de familiares de desaparecidos y sobrevivientes de las desapariciones, Nunca más derrumbó en la esfera pública el monopolio de la interpretación ejercido hasta entonces por las fuerzas armadas sobre los desaparecidos, al postular la existencia de un sistema clandestino de alcance nacional, bajo la responsabilidad de dichas fuerzas, que sirvió para perpetrar las desapariciones. Sin embargo, en su prólogo, el informe no explica históricamente el origen de la violencia política; propone a la violencia de Estado como respuesta a la violencia guerrillera; omite las intervenciones represivas que antecedieron en décadas al surgimiento de la guerrilla; presenta a las desapariciones como responsabilidad exclusiva de la dictadura y propone la ajenidad y la condición de víctima de la sociedad civil respecto de la violencia de Estado, omitiendo sus responsabilidades y las de la sociedad política en la violencia. ${ }^{14}$ Así, el prólogo del Nunca más propone un "nosotros", una "comunidad imaginada" externa a la violencia. Nunca más presenta a los desaparecidos por sus nombres, sexos, edades y ocupaciones, en sintonía con la narrativa forjada durante la dictadura por los familiares de desaparecidos, recalcando su ajenidad respecto de la guerrilla y de la militancia política (Crenzel, 2008). A partir de estos atributos, la comisión postula la condición de "víctimas inocentes" de los desaparecidos. Así, su denuncia de los derechos violados se asentó en la condición moral de las víctimas y no en el

14 COMISIÓN NACIONAL SOBRE LA DESAPARICIÓN DE PERSONAS (CONADEP). Nunca Más. Informe de la Comisión Nacional sobre la Desaparición de Personas. Buenos Aires: EUDEBA, 1984, 9 y 10. 
carácter universal de estos derechos. ${ }^{15}$ Las películas La historia oficial (1985), ganadora del Oscar a la mejor película extranjera en 1986, y La noche de los lápices (1986), ambas vistas por millones de espectadores y difundidas en televisión, reprodujeron estas claves interpretativas, evidenciando que trascendían a la conducción del Estado y conectaban con ideas de grupos diversos de la sociedad civil.

En el plano judicial, el intento de Alfonsín de no procesar a la mayoría de los cuadros militares a los que amparaba el alegato de obediencia, fue afectado rápidamente. En febrero de 1984, una enmienda del senador Elías Sapag, del Movimiento Popular Neuquino, tío de desaparecidos, excluyó del alegato de obediencia a los autores de hechos "atroces y aberrantes". Todas las prácticas que comportaron las desapariciones quedaban entonces pasibles de ser juzgadas, tal como reclamaban los organismos. Otro escollo a la estrategia oficial lo constituyó la decisión de la justicia militar que calificó de "inobjetables" las órdenes de las juntas. Tras esa declaración, en octubre de 1984, el fiscal de la Cámara Federal de Apelaciones de la Capital, Julio Strassera, pidió avocarse a la causa por interpretar esos actos como denegatorios de justicia.

El juicio a las juntas comenzó el 22 de abril de 1985 y supuso una decisión excepcional en el tratamiento de las violaciones a los derechos humanos en el continente. Los máximos responsables del poder dictatorial eran llevados a juicio. La fiscalía presentó 711 casos mayoritariamente producto de la investigación de la CONADEP para demostrar la responsabilidad conjunta y mediata de las juntas en la construcción de un aparato de poder con el cual perpetraron innumerables casos de privación ilegítima de la libertad; aplicaron sistemáticamente la tortura; eliminaron a los cautivos, cuyos bienes fueron saqueados y que este sistema de represión ilegal fue utilizado de manera indiscriminada más allá de la lucha contra la guerrilla. ${ }^{16}$

15 CRENZEL, Emilio. La historia política del Nunca Más. La memoria de las desapariciones en la Argentina. Buenos Aires: Siglo XXI, 2008.

16 Sobre el juicio a las juntas militares, véase ACUÑA, Carlos y SMULOVITZ, Catalina Smulovitz. Militares en la transición argentina: del gobierno a la subordinación constitucional. En GONZÁLEZ BOMBAL, Inés. Nunca Más. El juicio más allá de los estrados. En ACUÑA, Carlos; GONZÁLEZ BOMBAL, Inés; JELIN, Elizabeth; LANDI, Oscar; SMULOVITZ, 
Para ello, su estrategia se basó en el Nunca más. En primer lugar, presentó los casos de afectados que se alejaban de toda sospecha de pertenencia guerrillera pero también de militancia política y resaltó su indefensión. Esta táctica coincidió con la decisión de ciertos sobrevivientes de presentarse ante el tribunal como militantes políticos o sectoriales silenciando su militancia guerrillera. ${ }^{17}$ Además, la fiscalía evitó la apertura de nuevas confrontaciones que desviaran la acusación hacia actores que, antes o después del golpe, apoyaron la "lucha antisubversiva". Tampoco procuró establecer los nexos entre las desapariciones, las corporaciones económicas, religiosas y políticas, buscando que el juicio conjugara el enfrentamiento exclusivo entre la dictadura y la democracia. Así, el decreto de juzgamiento a las juntas y a las cúpulas guerrilleras y el Nunca más fueron los marcos políticos de la acusación y sus límites para interrogar el pasado.

Por su parte, las defensas adujeron la validez de la ley de amnistía de la dictadura y denunciaron el carácter "político" del juicio el cual, consideraron, cuestionaba a la fuerzas armadas victoriosas en la "guerra antisubversiva". Frente a la acusación, justificaron todo lo actuado en la "guerra antisubversiva" y negaron las denuncias concretas descalificando a los testigos por su condición "subversiva". Con igual sentido, atribuyeron la intervención militar a los decretos del gobierno peronista para dotarla de legalidad y procuraron demostrar que las desapariciones empezaron entonces, pero descalificaron a quienes denunciaron su práctica bajo la dictadura. Así, mientras la fiscalía y los testigos convocados por el tribunal silenciaron las pertenencias políticas de los desaparecidos para legitimar los derechos ciudadanos, las defensas buscaron exponerlos para negar la condición ciudadana de los testigos. Ambas estrategias ilustran los límites de la noción de ciudadanía de la democracia temprana en Argentina, ya que no asumieron en plenitud el carácter universal de los derechos humanos.

Catalina; QUEVEDO, Luis y VACCHIERI, Susana., Juicio, castigos y memorias. Derechos Humanos y justicia en la política Argentina, Buenos Aires: Nueva Visión, 1995, 21-99.

17 Sobre la decisión de los sobrevivientes, de mi entrevista a Graciela Daleo, Buenos Aires, 17 de junio de 2005 . 
El 9 de diciembre de 1985 el tribunal sentenció a los comandantes considerando que ejecutaron una represión ilegal con métodos clandestinos, pero desestimó la existencia de una conducción unificada. Por ello, determinó condenas disímiles para los generales Videla y Viola, los almirantes Massera y Lambruschini, y el brigadier Agosti, absolviendo a los otros cuatro acusados, el brigadier Graffigna, el general Galtieri, el almirante Anaya y el brigadier Lamidozo. En cambio, el punto 30 del fallo extendió la acción penal contra oficiales superiores en contra de la voluntad oficial de limitar los juicios.

El juicio a las juntas estableció la escena de la ley en la tramitación del pasado de violencia y, a la vez, como premisa fundacional de la comunidad política. Sin embargo, las fuerzas armadas rechazaron la sentencia calificándola de venganza subversiva, presionaron para clausurar los juicios en curso y liberar a los miembros de las juntas. Los organismos cuestionaron las absoluciones y redoblaron la lucha para ampliar los procesos penales. Así, los juicios se transformaron en una nueva fuente de conflictos. ${ }^{18}$

En función de la meta del gobierno de Alfonsín de limitar los juicios en el tiempo y en la cantidad de procesados, en abril de 1986 el Ministerio de Defensa instruyó a los fiscales para que sólo continuaran con los casos en los que "los subordinados actuaron con error insalvable" ante órdenes superiores, iniciativa que la Cámara Federal rechazó. En diciembre de 1986 el Ejecutivo envió al Congreso el proyecto de "Punto final" que establecía que, tras sesenta días, se extinguirían las causas de aquellos no citados a declarar. Pese al rechazo opositor y de los organismos, la ley se aprobó el 26 de diciembre de 1986, pero no evitó que antes de que expirara este plazo los organismos presentasen ante las cámaras federales centenares de casos.

En abril de 1987 se produjo la sublevación de un sector del ejército que rechazaba la continuidad de los juicios. Ciento cincuenta mil personas reunidas en la Plaza de Mayo rechazaron la sublevación.

18 MALAMUD GOTi, Jaime. Terror y justicia en la Argentina. Responsabilidad y democracia después de los juicios al terrorismo de Estado. Buenos Aires: Ediciones de la Flor, 2000, 215-231. 
Tras ello, el gobierno envió al Congreso un nuevo proyecto de ley de obediencia debida, que consideraba todo acto - excepto la sustitución del estado civil, la sustracción de menores y la usurpación de propiedad-, como ejecutados bajo estado de coerción y subordinación a órdenes superiores. Pese a la aprobación de esta ley, Alfonsín enfrentó dos nuevas rebeliones militares en enero y diciembre de 1988. Finalmente, un proceso hiperinflacionario condujo a la entrega anticipada del gobierno al peronista Carlos Menem, triunfador en las elecciones.

Tras asumir la presidencia el 9 de julio de 1989, Menem proclamó su intención de "reconciliar" y "pacificar" a la sociedad "resolviendo la cuestión militar" y clausurando las querellas que dividieron al país desde el siglo XIX. ${ }^{19}$ Pese al rechazo internacional del $90 \%$ de la población y movilizaciones de 100000 personas, el 7 de octubre de 1989 dictó los decretos 1002, 1003,1004 y 1005 indultando a militares procesados por violaciones a los derechos humanos, sublevados contra el gobierno de Alfonsín, y a guerrilleros procesados. Tras un nuevo levantamiento militar, el 29 de diciembre de 1990 dictó los decretos 2741, 2742, 2743, 2744, 2745 y 2746 que beneficiaron a los miembros de las juntas presos, a otros responsables de violaciones a los derechos humanos y al jefe de Montoneros, Mario Firmenich. Los indultos, de este modo, reponían en escena la "teoría de los dos demonios".

\section{El eclipse de la memoria (1990-1994)}

El indulto produjo un gran impacto moral y político entre los organismos de derechos humanos. El "duelo" público al que convocaron para repudiarlo, condensaba la sensación de clausura de toda posibilidad de justicia. De hecho, tras esa medida sus 10.

19 SABATO, Hilda. Olvidar la memoria. Punto de Vista Buenos Aires, 36 (1989): 8- 
movilizaciones disminuyeron en regularidad y convocatoria. Otro tanto sucedió con las producciones culturales sobre el periodo de violencia. Las películas sobre estos temas, excepto el film Un muro de silencio (1993) de Lita Stantic, tuvieron escasa repercusión. Además del impacto del indulto, este "enfriamiento" de la presencia del pasado fue fruto de los rápidos y profundos cambios económicos del periodo que concentraron la atención pública: la privatización de las principales empresas estatales, el despido de miles de empleados y las políticas de apertura económica. Al decretarse el indulto, diversas encuestas registraban que $38 \%$ de los consultados lo consideraban la peor medida del gobierno de Menem. Un año después, en diciembre de 1991, 7\% de los consultados sostenía esa afirmación y sólo 1\% consideraba a los derechos humanos el problema más urgente del país. En 1994 este tema no era mencionado por la población, que priorizaba el desempleo, la estabilidad cambiaria y la corrupción. ${ }^{20}$

Asimismo, tras el indulto, las fuerzas armadas se replegaron de la escena pública y luego fueron redimensionadas al calor de las políticas de reforma del Estado y en función del nuevo contexto internacional y regional signado por el fin de la Guerra Fría, los acuerdos limítrofes con Chile y la constitución con Brasil, como socio principal, del Mercado Común del Sur (Mercosur), que pusieron fin a las hipótesis de conflicto con ambos países vecinos.

En este nuevo contexto, los organismos dirigieron a la Comisión Interamericana de Derechos Humanos su demanda de justicia. La CIDH recomendó reparar a las víctimas y señaló la incompatibilidad de las leyes e indultos con la Declaración Americana de los Deberes y Derechos del Hombre y con la Convención Interamericana de Derechos Humanos. Simultáneamente, en Francia, España, Italia y Suecia se retomaron juicios por violaciones a los derechos humanos perpetradas en Argentina. Ante la presión de la CIDH, el gobierno de Menem otorgó mediante la Ley 24.043, en noviembre de 1991, una reparación a los detenidos a disposición del Poder Ejecutivo entre el 6 de noviembre de 1974, al declararse el estado de sitio, y el 10 de diciembre de 1983,

20 Véase Sergio Ciancaglini, “Qué nos preocupa a los argentinos," Clarín, 5 de junio de 1994: portada, 2 y 5 . 
presentándose 12.890 demandas. Asimismo, sancionó la Ley 24.411 "de beneficio a las personas ausentes por desaparición forzada y a las fallecidas por el accionar de las Fuerzas Armadas", reglamentada el 29 de agosto de 1995, que estableció reparaciones económicas para sus familiares de hasta 220 mil dólares. Hubo 3.151 presentaciones por personas asesinadas y 8.950 por personas desaparecidas.

Las leyes reparatorias dividieron a los organismos. Mientras la Asociación Madres de Plaza de Mayo la rechazó argumentando que su autor era el Estado que denegaba justicia y cuestionó a quienes las aceptaban, el resto argumentó que significaba un reconocimiento oficial de las violaciones que no impedía seguir reclamando la sanción de los culpables.

En 1994 se incorporó, con rango constitucional superior a las leyes locales, una serie de tratados internacionales de protección y defensa de los derechos humanos. Pero, al mismo tiempo, la creciente pérdida de derechos sociales, la violencia policial y los ataques terroristas en Buenos Aires contra la embajada de Israel en 1992 y contra la Asociación Mutual Israelita Argentina (AMIA) en 1994 -los cuales provocaron 29 y 85 muertos-, provocaban una sensación de anomia e indefensión. La condición ciudadana combinaba la incorporación normativa de derechos con el recorte de la capacidad efectiva de ejercerlos. En ese marco, el presente fue leído como la imagen espectral del pasado sin derechos. El presidente Menem identificó a la protesta social con la "subversión"; las Madres de Plaza de Mayo igualaron a los afectados por las políticas económicas neoliberales con los desaparecidos; la protesta social incorporó ciertas prácticas de los organismos y éstos incorporaron sus demandas. ${ }^{21}$

21 Sobre la incorporación mutua de demandas y prácticas entre los organismos de derechos humanos y los movimientos de protesta social, véase FILC, Judith. La memoria como espacio de confrontación política. Los relatos del horror en Argentina. Apuntes de investigación del CECYP Buenos Aires: CECYP, II, 2/3, 37-53, 1998. 


\section{La explosión de la memoria (1995-2003)}

Tras años de relativo silencio, en febrero de 1995 el debate público de las violaciones a los derechos humanos regresó al primer plano a partir de las declaraciones del capitán Adolfo Scilingo quien narró su participación en operativos en los cuales arrojó desaparecidos con vida al mar desde aviones de la Marina. ${ }^{22}$ Sus declaraciones causaron un gran impacto y suscitaron otras confesiones de oficiales y suboficiales, las cuales sólo se interrumpieron cuando el jefe del ejército, Martín Balza, realizó una autocrítica pública en la cual impugnó la intervención militar en la vida política y rechazó la obediencia a la autoridad como justificación de crímenes.

Tras estas declaraciones la memoria del pasado de violencia se revitalizó y adquirió un estatus específico, independiente de la meta punitiva o de la búsqueda de la verdad, en la agenda del movimiento de derechos humanos, de los poderes públicos y los medios de comunicación. Por un lado, ello se debió al creciente reconocimiento del proceso de tránsito generacional que la proximidad del vigésimo aniversario del golpe de Estado de 1976 ponía de relieve y a la toma de conciencia de que las nuevas generaciones ignoraban aspectos sustantivos de esa historia y que era necesario constituir vehículos o soportes que asegurasen la transmisión intergeneracional. Por otra parte, la inexistencia de un contexto punitivo habilitó el surgimiento de las memorias de la militancia, en especial la armada, cuyos portadores habían sido perseguidos y estigmatizados por la dictadura y luego habían sido objeto, ya en democracia, de la persecución penal hasta los indultos. Es decir, las memorias de la política surgieron en un contexto signado por la anulación del escenario jurídico, hasta entonces territorio casi exclusivo donde se tramitaba este pasado. Por último, surgió una nueva generación dentro del movimiento de derechos humanos -los

22 Para las declaraciones de Scilingo, véase Verbitsky, Horacio. El vuelo. Buenos Aires: Planeta, 1995. 
hijos de los desaparecidos-, que interrogó con otras claves este pasado y a sus protagonistas.

Las iniciativas por constituir diversos puentes para la transmisión intergeneracional asumieron diversas formas. En primer lugar, desde el verano de 1994, por iniciativa de los organismos y compañeros de estudio o de trabajo de los desaparecidos, se conformaron "comisiones por la memoria" en facultades, colegios, sindicatos y barrios para reconstruir los nombres y biografías públicas y privadas de los desaparecidos. En segundo lugar, el movimiento de derechos humanos en alianza con diversos estados, en especial de las ciudades de Buenos Aires y Rosario gobernadas por alianzas de centroizquierda, impulsó la constitución de lugares de memoria: museos, archivos, parques o marcas en las topografías urbanas, como placas y baldosas, que objetivaran el recuerdo de las víctimas.

Una de estas iniciativas fue la creación, en Buenos Aires, por ley 46 de 1998, del Parque de la memoria, a orillas del Río de La Plata, donde se erigió el Monumento a las víctimas del terrorismo de Estado, en el cual se inscribieron los nombres de los desaparecidos y asesinados.

Pese a la aparente unanimidad de criterios sobre la existencia de "víctimas" fruto del "terrorismo de Estado", pronto surgieron fuertes divergencias en la comisión promotora del monumento, compuesta por legisladores de la ciudad (muchos de ellos militantes revolucionarios en los años setenta), y representantes de los organismos. La comisión debatió desde cuándo considerar la existencia del "terrorismo de Estado" (si desde antes o tras el inicio de la dictadura), ya que centenares de víctimas correspondían al periodo de los gobiernos constitucionales peronistas (1973-1976); si incluir entre las víctimas a los guerrilleros muertos en combate y si inscribir sólo los nombres de los desaparecidos registrados oficialmente o presentar la cifra de 30.000 , enarbolada por los organismos. Estas discusiones pusieron de manifiesto que tanto la categoría de "víctima" como la de "terrorismo de Estado", lejos de revestir meramente una condición objetiva eran fruto de las luchas políticas cuyo resultado determina la inclusión y la exclusión de 
identidades y fija la periodización del pasado, operaciones, ambas, que determinan las fronteras de estas categorías. ${ }^{23}$

Otras iniciativas para inscribir topográficamente la memoria de las víctimas de la violencia de Estado, fueron resistidas por las instituciones armadas y el gobierno de Carlos Menem. Específicamente, el presidente Menem propuso en 1998 demoler la Escuela de Mecánica de la Armada (ESMA), uno de los más importantes centros clandestinos de detención, donde estuvieron cautivos cerca de 5.000 desaparecidos, y erigir allí un "monumento a la unidad nacional". Los organismos, mediante una presentación judicial, paralizaron esa iniciativa e impulsaron, en 2000, junto a concejales de centroizquierda de la ciudad de Buenos Aires, la Ley 392 que dispuso destinar la ESMA a un museo de la memoria. Los primeros debates sobre el contenido de este museo incluyeron la discusión de estrategias para restituir la historia política de los desaparecidos; establecer puentes narrativos entre las desapariciones; los atentados a la AMIA y a la embajada de Israel; la desigualdad social y, como en el caso del monumento, la condición de "víctimas" de los desaparecidos y la periodización del terrorismo de Estado. Así, el consenso narrativo del Nunca más fue crecientemente puesto en discusión. ${ }^{24}$

Por último, la transmisión de este pasado se cristalizó en la renovación de los contenidos de los textos escolares de historia y educación cívica de la escuela media. Estos textos habían permanecido casi sin modificaciones desde los cambios introducidos por la dictadura, que presentaban la intervención militar del 24 de marzo de 1976 como una gesta patriótica que había salvado al país de la "subversión", omitían la palabra "golpe de Estado" y la existencia de desaparecidos. Los nuevos textos incorporaron al relato de la historia reciente la asociación entre el golpe de 1976 y la implantación de un modelo económico regresivo y excluyente y

23 Al respecto, véase VECCHIOLI, Virginia. "Políticas de la memoria y formas de clasificación social ¿Quiénes son las ‘víctimas' del Terrorismo de Estado en Argentina?” En $L a$ imposibilidad del olvido. Recorridos de la memoria en Argentina, Chile y Uruguay En Bruno GROPPO y Patricia FLIER (eds.), La Plata: Al Margen, 2001, 83-102.

24 Véase MEMORIA ABIERTA. Primeras Jornadas de debate interdisciplinario. Organización institucional y contenidos del futuro museo de la memoria. Buenos Aires: Dirección Municipal de Museos, 2000. 
presentaron a los desaparecidos como sujetos de derecho y, en algunos casos, como militantes políticos. ${ }^{25}$

Este cambio en la literatura escolar fue paralelo a la emergencia de memorias militantes, en libros biográficos o autobiográficos, que buscaron confrontar la perspectiva del Nunca más porque, entendían, ocultaba, tras un manto de inocencia, la militancia de los desaparecidos. Los libros testimoniales carecieron de una perspectiva analítica y propusieron una nueva literatura de las virtudes, resaltando los ideales de la militancia y su compromiso con el cambio social pero excluyendo la crítica de la violencia política. Así, reprodujeron, bajo otras formas, el aura de inocencia que extendió la CONADEP sobre los desaparecidos, aunque sus compromisos políticos y la propia política como claves para explicar las tensiones que surcaron esa época. ${ }^{26}$

Por último, en 1995 se conformó Hijos contra la impunidad, por la justicia, contra el olvido y el silencio (H.I.J.O.S.), organización que agrupó a los descendientes de los desaparecidos y que, desde su constitución, discutió la perspectiva del Nunca más al cuestionar al Estado por la ausencia de justicia, enfrentar la "teoría de los dos demonios" y rescatar la militancia política de sus padres desaparecidos, pero también a la sociedad por su "olvido y silencio". Películas como Papá Iván (2000), de María Inés Roqué, y Los rubios (2003) de Albertina Carri, ambas hijas de desaparecidos, ilustran estos dilemas. Así, el surgimiento de H.I.J.O.S. evidenció que la elaboración del pasado es producto de la transmisión de quienes tuvieron experiencia de él pero también de la voluntad de saber de las nuevas generaciones. En el acto masivo de marzo de 1996, al cumplirse el vigésimo aniversario del golpe, las Madres de Plaza de Mayo traspasaron simbólicamente la lucha humanitaria a H.I.J.O.S,

25 BORN, Diego, TSCHIRNHAUS, Hernán y MORGAVI, Martín. De cómo los desaparecidos se hacen presente en el colegio. Los textos escolares de historia de nivel medio en la ciudad de Buenos Aires (1980-2001). En CRENZEL, Emilio (ed.) Desapariciones y violencia política en Argentina. Representaciones, imágenes e ideas (1983-2008), Buenos Aires: Biblos, 2010, 189-210.

26 Para el más representativo de estos libros, véase ANGUITA, Eduardo, y CAPARRÓS, Martín. La Voluntad. Testimonios de la militancia revolucionaria. Buenos Aires: Norma, 1996. 
escenificando el nuevo lugar que la memoria y su transmisión habían adquirido en la esfera pública. ${ }^{27}$

\section{La estatalización de la memoria (2003-2012)}

Tras la crisis económica, política y social de 2001 que culminó con la renuncia del presidente radical Fernando de la Rúa, y tras el interinato de Eduardo Duhalde, el presidente peronista Néstor Kirchner (2003-2007), impulsó una serie de iniciativas que modificaron el escenario de luchas por los derechos humanos. En el plano judicial, tras el pedido del juez español Baltazar Garzón de extradición de 46 militares acusados de genocidio, el presidente Kirchner decidió derogar el decreto que impedía la extradición a partir del principio de territorialidad y el 12 de agosto de 2003, a propuesta de Patricia Walsh, diputada de izquierda e hija del escritor y militante Rodolfo Walsh desaparecido durante la dictadura, el congreso anuló las leyes de Punto Final y Obediencia Debida, decisión que tenía por antecedentes la derogación de ambas leyes el 24 de marzo de 1998 y la declaración, del 6 de marzo de 2001, del juez federal Gabriel Cavallo, quien había declarado su inconstitucionalidad.

La derogación de las leyes de impunidad permitió reanudar los juicios, los cuales fueron rechazados por los represores y sus aliados aduciendo que constituían "juicios políticos". Asociaciones como "Memoria completa", denunciaron las políticas oficiales retomando el discurso castrense que proponía como víctimas a las fuerzas amadas de la subversión, ahora encarnada en el gobierno de Kirchner. En estos procesos se reunió nueva evidencia, pero también fue clave la recabada por la CONADEP, el juicio a las juntas y la

27 Sobre la conmemoración del vigésimo aniversario del golpe, véase LORENZ, Federico. ¿De quien es el 24 de Marzo? Las luchas por la memoria del golpe de 1976. En JELIN, Elizabeth Las conmemoraciones: las disputas en las fechas in-felices, Madrid: Siglo XXI, 2002, 53 100 . 
presentada en los "juicios por la verdad", una original estrategia jurídica impulsada desde 1998 por el CELS la cual, sin metas punitivas, se desarrolló en varios ciudades del país. ${ }^{28}$ Hasta julio de 2016, 2.071 personas, en su mayoría militares y policías, estuvieron o están involucradas en causas por violaciones a los derechos humanos. De ellos, 370 fueron condenadas, entre ellas los generales Jorge Videla, Antonio Bussi y Luciano Benjamín Menéndez, así como los marinos Jorge Acosta y Alfredo Astiz, figuras emblemáticas de la represión. ${ }^{29}$

La reanudación de los juicios reafirmó la centralidad de los tribunales en la elaboración de la verdad y el ejercicio de la memoria, escenario donde prima el relato realista de las vejaciones. Como novedad, varias sentencias condenatorias consideraron que los delitos perpetrados se produjeron en el marco de un genocidio. Esta caracterización era impulsada por ciertos organismos de derechos humanos, y adquirió renovada potencia con el fallo del 4 de noviembre de 1998 del Pleno de la Sala de lo Penal de la Audiencia Nacional de España, al intervenir en la causa donde luego se condenó al marino Scilingo por los crímenes perpetrados en la ESMA. Dado que la definición de genocidio excluye a los grupos políticos, las sentencias postularon que mediante las desapariciones y otros delitos, se procuró destruir a un "grupo nacional" específico, una porción de la sociedad argentina, aquella que cuestionaba los valores del orden establecido. ${ }^{30}$ Las ideas de Daniel Feierstein, citado en estos fallos, contribuyeron a esta caracterización. Creyente fervoroso de que la represión en Argentina replicó el genocidio nazi, Feierstein fuerza las categorías jurídicas para que se subordinen a sus ideas. Así, propone a los desaparecidos como un "grupo nacional" y oblitera que, lejos de constituirlo, eran, mayoritariamente, militantes políticos de izquierda,

28 Para el análisis de un juicio por la verdad, véase ANDRIOTTI ROMANIN, Enrique. Memorias en conflicto. El Movimiento de derechos humanos y la construcción del Juicio por la Verdad de Mar del Plata, Mar del Plata: Editorial Universitaria de Mar del Plata, 2013.

29 Para un panorama de los juicios en curso, véase http://www.cels.org.ar/comunicacion/?info=detalleDoc\&ids $=4 \&$ lang=es \&ss $=46 \&$ idc $=1246$ [Consulta: 13 de enero de 2016].

30 Véase la sentencia en el juicio al comisario Miguel Etchecolatz, La Plata, 19 de septiembre de 2006 en http://www.derechos.org/nizkor/arg/ley/etche.html [Consulta: 16 de julio de 2016] 
peronistas y marxistas. Así, pese a su aparente radicalidad, este planteo reproduce la despolitización de los desaparecidos y tergiversa la historia argentina reciente, la del genocidio nazi y la identidad de las víctimas de ambos procesos. ${ }^{31}$

La administración de Néstor Kirchner, además, impulsó en 2006 la reedición del informe Nunca más al cumplirse el trigésimo aniversario del golpe. Como novedad, esta edición incluyó un nuevo prólogo escrito por la Secretaria de Derechos Humanos de la Nación conducida por Eduardo Luis Duhalde y Rodolfo Mattarollo, quienes militaron en organizaciones revolucionarias de los años setenta, fueron defensores de presos políticos y denunciaron a la dictadura desde el exilio.

La adición del nuevo prólogo confirmó la importancia del Nunca más en las ideas y representaciones de la sociedad argentina sobre esos hechos, ya que la iniciativa lo transformó en un instrumento para exponer una nueva lectura oficial sobre el pasado de violencia. ${ }^{32}$

El nuevo prólogo refleja la impronta fundacional con la cual se presentó el gobierno de Kirchner respecto de sus predecesores constitucionales. Estas políticas son calificadas como parte de un momento "histórico" y "excepcional", fruto de la política oficial y de su encuentro con "las inclaudicables exigencias de verdad, justicia y memoria mantenidas por nuestro pueblo a lo largo de las últimas tres décadas". Asimismo, tras asociar el terror de Estado con la imposición de un modelo económico excluyente, el nuevo prólogo postula el sintagma "Nunca más" para los crímenes de Estado pero, también, la desigualdad social. Pero, en especial, confronta la explicación de la CONADEP sobre el proceso de violencia, a la cual presenta como una "simetría justificatoria" entre la violencia guerrillera y estatal y hace suya, pese a los registros oficiales

31 FEIERSTEIN, Daniel. El genocidio como práctica social. Entre el nazismo y la experiencia argentina. Buenos Aires: Fondo de Cultura Económica, 2007. 200315 de Noviembre. Para una temprana crítica a sus ideas, véase CRENZEL, Emilio. La memoria de la desaparición de personas y el tropos del genocidio nazi. Ponencia presentada en el "Primer Encuentro Internacional: Análisis de las prácticas sociales genocidas", Facultad de Derecho, Universidad de Buenos Aires, Buenos Aires, 2003.

32 CRENZEL, Emilio. La historia política del Nunca Más. La memoria de las desapariciones en la Argentina. Buenos Aires: Siglo XXI, 2008, 172. 
existentes, la cifra de 30.000 desaparecidos enarbolada por los organismos. $^{33}$

En síntesis, el nuevo prólogo al Nunca más transformó en discurso estatal un sentido del pasado forjado desde el vigésimo aniversario del golpe, cuando los organismos asociaron los crímenes dictatoriales con la imposición del modelo económico neoliberal. Pese a ello, al igual que el prólogo original, no historiza la dictadura ni el proceso de violencia política y omite las responsabilidades del Estado, las fuerzas armadas, la sociedad política y civil en las desapariciones previas al golpe. A la vez, postula la relación de la sociedad argentina con el horror desde una mirada inversa al original pero igual de totalizante en la que el pueblo, sin fisuras, lo enfrenta eclipsando, así, la soledad de los denunciantes del crimen durante la dictadura. Pese al discurso oficial del gobierno de Kirchner, que valorizó la militancia de los años setenta, el prólogo de 2006 reproduce el retrato de los desaparecidos del prólogo original. Los presenta por sus datos identitarios básicos (niños, jóvenes, hombres y mujeres de todas las edades); sus perfiles ocupacionales (obreros, periodistas, abogados, psicólogos, profesores universitarios, docentes, estudiantes), o como hombres y mujeres de todos los estamentos sociales. Prolonga, así, una imagen indiscriminada, que retoma la narrativa humanitaria forjada durante la dictadura que excluyó, como la CONADEP, a la guerrilla y a la militancia política de ese universo. $^{34}$

En este periodo, las iniciativas oficiales abarcaron también la creación de "lugares de memoria". Se incorporó en 2006 al calendario oficial el feriado del 24 de marzo como el "Día Nacional de la Memoria por la Verdad y la Justicia" y, ese día en 2004, en un acto público en la ESMA, se creó el "Espacio para la Memoria y para la Promoción y Defensa de los Derechos Humanos", bajo responsabilidad de la nación y la ciudad de Buenos Aires y representantes de los organismos. Allí, el presidente Kirchner

33 SECRETARÍA DE DERECHOS HUMANOS DE LA NACIÓN. Prólogo. En COMISIÓN NACIONAL SOBRE LA DESAPARICIÓN DE PERSONAS. Nunca Más. Informe de la Comisión Nacional sobre la Desaparición de Personas. Buenos Aires: EUDEBA, 2006,7 y 8.

34 CRENZEL, Emilio. La historia política del Nunca Más. La memoria de las desapariciones en la Argentina. Buenos Aires: Siglo XXI, 2008, 172-179. 
impugnó la "teoría de los dos demonios" y pidió perdón por el "silencio del Estado" en los veinte años de democracia. El discurso recibió el apoyo de la mayoría de los organismos, pero provocó la objeción de sectores opositores por la omisión de iniciativas estatales como la CONADEP o el juicio a las juntas, que deshistorizaba la acción estatal que el discurso presidencial reivindicaba.

La constitución de los ex centros clandestinos en sitios de memoria, evidencia el avance en la lucha contra el olvido y la impunidad de los crímenes de Estado. Este proceso, sin embargo, revela aristas conflictivas. Por un lado, sus nóveles burocracias evidencian la disolución de las fronteras entre la sociedad civil y el Estado, dado el simultáneo ejercicio de la función pública con la pertenencia a un organismo o asociación de víctimas. Ello se ha traducido en la pérdida de autonomía del movimiento de derechos humanos al diluir su distancia con el Estado y en la ausencia de una política estatal que tome en cuenta estas voces pero que no se subordine a ellas. Es posible pensar que las fronteras entre lo decible y lo silenciado en estos sitios expresan dificultades comunes a actores estatales y de la sociedad civil para inscribir las violaciones a los derechos humanos, y a sus perpetradores y víctimas en términos históricos y políticos. Es decir, para formular una política de la memoria que incorpore la memoria de la historia y la política como claves de su relato.

El lugar de memoria visitado por Obama y Macri, el Parque de la Memoria- Monumento a las Víctimas del Terrorismo de Estado, fue inaugurado en noviembre de 2007. Tras arduas discusiones, el monumento presentó el ejercicio del "terrorismo de Estado" más allá de la dictadura, al considerarse el período 1970-1983. Los nombres de los desaparecidos y asesinados fueron inscritos cronológicamente, dejándose placas en blanco hasta completar 30.000 en función del emblema de los organismos y se omitió toda referencia a las adscripciones políticas de las víctimas, que evidencia la dificultad para integrar sus compromisos en una política oficial de la memoria.

En el caso de la ESMA, tras varios años, se hizo efectivo el desalojo de los institutos militares del predio, sus edificios fueron cedidos por el Estado a los organismos, excepto el CELS, que decidió autoexcluirse. Cada organismo dispone con autonomía para el uso de cada instalación, situación que se tradujo en la ausencia de una 
política coordinada. ${ }^{35}$ La elaboración del relato museístico tampoco fue el resultado de un consenso amplio y deliberativo y el uso del predio suscitó fuertes polémicas públicas. La de mayor repercusión sucedió cuando se realizaron asados, con participación de murgas, que reunieron a funcionarios $\mathrm{y}$ militantes oficialistas. Ante las denuncias de sobrevivientes de la ESMA, la presidenta Cristina Kirchner afirmó que "En la ex-ESMA se han hecho y se seguirán haciendo asados. Es la vida que por fin alcanza un lugar donde reinaron la muerte, el dolor, la tragedia y también las miserias humanas" insistiendo, así, en la necesidad de "resignificar" los centros clandestinos "recuperados". ${ }^{36} \mathrm{La}$ "recuperación" alude a algo que se imagina propio y fue perdido y traduce una particular concepción de la relación entre el pueblo y las Fuerzas Armadas y policiales. La "resignificación" de los centros clandestinos, mediante la realización de actividades banales con el argumento de que desafían la apuesta de los perpetradores de negar la vida, desplaza los crímenes dictatoriales de la historia y la política, al enajenarlos de la vida institucional del país. La muerte, que transcurrió en la vida política argentina sufre, como hizo notar Phillipe Ariès al analizar la cultura occidental, su interdicción. ${ }^{37}$

Tras la asunción de la presidencia Macri, en diciembre de 2015 , se ha verificado un marcado retroceso de las políticas de memoria, verdad y justicia. Según los abogados querellantes en juicios por crímenes de lesa humanidad, en este breve lapso se desmantelaron parcial o totalmente áreas que investigaban la responsabilidades corporativas con los crímenes dictatoriales, que aportaban pruebas a los juicios y/o asistían a las víctimas -entre ellos el Grupo Especial de Relevamiento Documental, el Programa Verdad y Justicia, el Centro de Asistencia a Víctimas de Violaciones de Derechos Humanos Dr. Fernando Ulloa, la Subgerencia de Promoción de los Derechos Humanos del Banco Central-. En otros

35VEZZETTI, Hugo. Sobre la violencia revolucionaria. Memorias y olvidos. Buenos Aires: Siglo XXI, 2009, 217-230.

36 Denuncian nuevos "asados" de funcionarios del Gobierno en la ex ESMA. La Nación ,2 de septiembre de 2013 http://www.lanacion.com.ar/1616295-denuncian-indignacion-ylagrimas-por-nuevos-asados-de-funcionarios-en-la-ex-esma [Consulta: 10 de agosto de 2016]

37 ARIÉS, Philippe. Western Attitudes Toward Death: from the Middle Ages to the Present. Baltimore: The Johns Hopkins University Press, 1974. 
casos, se designó personal militar para dirigir el Programa Nacional de Protección de Testigos. ${ }^{38}$ En paralelo, la genérica condena de la violencia y las referencias de igual tono a las víctimas marcan un giro discursivo que deja de lado el carácter distintivo de los crímenes de la última dictadura. Se comienza a asistir, entonces, a un nuevo ciclo en este largo proceso de luchas en el cual la voz del Estado vuelve a confrontarse con las ideas y políticas del movimiento de derechos humanos. Ello evidencia que el sentido del pasado no está definido de una vez y para siempre y que la historia de la confrontación por el sentido de la dictadura y sus crímenes se sigue escribiendo en el presente.

\section{Conclusiones}

A 40 años del comienzo de la última dictadura en la Argentina, la memoria social sobre sus crímenes permanece viva. La historización de sus memorias revela la coexistencia y lucha permanente, desde que se produjeron los hechos, entre diversos sentidos y representaciones, y la relación entre estas luchas con los diversos contextos políticos que las fueron modelando y modificando.

A la interpretación dictatorial que enmarcaba su propia intervención golpista como una gesta salvadora y entendía el proceso de violencia como fruto de una "guerra antisubversiva", quienes denunciaron sus crímenes respondieron incorporando el discurso de los derechos humanos, en expansión a escala internacional a mediados de los años setenta del siglo XX. La transición a la democracia en Argentina, signada por la derrota en la guerra de Malvinas y el triunfo electoral de Alfonsín, hicieron que el país se distinguiera por sus políticas de justicia transicional. Argentina fue pionera al formar una comisión de la verdad exitosa y enjuiciar a los

38 Página/12, Del dicho al hecho, nota de Victoria Ginzberg, 15 de agosto de 2016. Disponible en: http://www.pagina12.com.ar/diario/elpais/1-306881-2016-08-15.html [Consulta: 16 de agosto de 2016]. 
máximos responsables de los crímenes de la dictadura. Estas iniciativas derrumbaron el monopolio de la interpretación ejercido hasta entonces por los perpetradores. Bajo el gobierno de Alfonsín, el discurso oficial incorporó la narrativa humanitaria forjada durante la dictadura por sus denunciantes, y la encuadró en los marcos del derecho penal subordinado, a su vez, a la "teoría de los dos demonios", cuya funcionalidad estribaba en legitimar el monopolio estatal del uso de la fuerza y en evitar la revisión de las responsabilidades de la sociedad política y civil en el proceso de violencia.

La memoria de la política comenzó a emerger cuando la vía judicial se había aparentemente cerrado tras los indultos. En este contexto, la memoria cobró autonomía de las metas de verdad y justicia. Despojada de los límites del discurso jurídico, fue incorporando, la memoria de la militancia revolucionaria, asoció las violaciones a los derechos humanos con la transformación económica y la ampliación de las desigualdades sociales producidas por la dictadura y revisó la periodización de las violaciones a los derechos humanos incorporando las ocurridas antes del golpe de Estado. Desde 2003, muchas de estas ideas fueron asumidas por los gobiernos de Néstor y Cristina Kirchner.

Al examinar esta larga trayectoria, es evidente el papel que desempeñó el Estado en la configuración de representaciones e ideas sobre este pasado pero, sobre todo, el rol decisivo de los organismos de derechos humanos. Estos actores tenaces prefiguraron, en contextos desfavorables (la dictadura, los gobiernos de Menem), los discursos que el Estado en buena medida asumió más tarde como propios (gobiernos de Alfonsín y Kirchner). Es decir, para comprender la trayectoria y dinámica de la historia de la memoria de la dictadura y los desaparecidos en la Argentina, es necesario trascender las miradas economicistas de la memoria que explican la hegemonía de determinadas concepciones sobre el pasado como fruto mecánico de la voluntad del poder.

Más allá de ignorar que memorias circulan en amplios sectores de la sociedad argentina, especialmente los trabajadores y en el interior del país, la historia de la memoria de la dictadura evidencia la indudable derrota de la voluntad de dejar impunes y olvidar sus crímenes y de que la sociedad celebrase su victoria en la "guerra 
antisubversiva". La escena de Obama y Macri en el Parque de la Memoria sería impensada sin esa derrota. Sin embargo, las características de la verdad elaborada sobre estos crímenes, su tramitación jurídica y su inscripción en la memoria social, nos advierten de la perdurabilidad de una matriz de sentido que rehúye la dimensión histórica y política de los enfrentamientos que desgarraron a esta sociedad, incluyendo las responsabilidades de otros actores que, además de las fuerzas armadas, los tornaron posibles. Otro tanto ocurre al omitirse los compromisos políticos de los desaparecidos. Estas obliteraciones trascendieron, aún, las iniciativas de gobiernos y actores que se propusieron quebrar el legado dictatorial. Y, por ello, su persistencia evidencia los límites de la memoria sobre este pasado y la propia incorporación de la cultura de los derechos humanos. En estas páginas se intentó poner en evidencia estos límites revelan las dificultades que, aún hoy, perviven en la sociedad argentina para evocar, pensar e interrogar su pasado más trágico e inscribirlo en un relato que tenga a la política y a la historia como sus claves interpretativas. La apertura de un nuevo escenario, con la presidencia Macri, abre diversos interrogantes. En especial, pondrá a prueba el grado de institucionalización de las políticas de derechos humanos y la capacidad del "nosotros" que la ha sostenido de enfrentar la política regresiva del ejecutivo. La historia de la memoria de la dictadura, a cuarenta años, se sigue escribiendo.

RECEBIDO EM: 31/08/2016 APROVADO EM: 20/10/2016 